\title{
UM OLHAR SOCIOLÓGICO SOBRE OS CONCEITOS DE JUVENTUDE E DE PRÁTICAS CULTURAIS: Perspetivas e REFLeXões
}

\section{CATARina Doutor ${ }^{1}$}

\begin{abstract}
RESUMO
O presente artigo centra-se numa reflexão em torno das diversas perspetivas teóricas dos conceitos juventude e práticas culturais. Sendo assim, as principais questões que constituíram o ponto de partida desta investigação foram as seguintes: $\mathrm{O}$ que se entende por juventude? O que é ser jovem no mundo atual? O que se entende por práticas culturais? Dado que ambos os conceitos possuem, claramente, um inegável carácter polissémico, pretende-se enfatizar a importância dos jovens e, por conseguinte, das suas práticas culturais nas sociedades contemporâneas. Estas práticas culturais são, portanto, fundamentais para a vidaquotidiana das pessoas e principalmente dos jovens.
\end{abstract}

Palavras Chave: Jovem, Lazer E Tempos Livres

\section{UNA MIRADA SOCIOLÓGICA SOBRE LOS CONCEPTOS DE JUVENTUD Y PRÁCTICAS CULTURALES: \\ Perspectivas Y RefleXiones}

\begin{abstract}
RESUMEN
Este artículo se centra en una reflexión en torno a las diversas perspectivas teóricas de los conceptos de juventud y prácticas culturales. Las principales interrogantes que constituyeron el punto de partida de esta investigación fueron las siguientes: ¿Qué se entiende por juventud? ¿Qué es ser joven en el mundo actual? ¿Qué se entiende por prácticas culturales? Dado que ambos conceptos tienen un carácter polisémico innegable, el objetivo de esta investigación es enfatizar la importancia de los jóvenes y sus prácticas culturales en las sociedades contemporáneas. Estas prácticas culturales son, por lo tanto, fundamentales para la vida cotidiana de las personas y principalmente de los jóvenes.
\end{abstract}

PALABRAS ClAVE: JOVEN, OCIO Y TIEMPO LIBRE.

\section{A SOCIOLOGICAL LOOK AT THE CONCEPTS OF YOUTH AND CULTURAL PRACTICES: PERSPECTIVES AND REFLECTIONS}

\begin{abstract}
Based on the clearly undeniable, polysemic nature of the concepts of youth and cultural practices, this article focuses on a reflection on the various theoretical perspectives. The

\footnotetext{
${ }^{1}$ Portuguesa, licenciada em Sociologia e Mestre em Educação Social pela Universidade do Algarve. Atualmente é estudante de Doutoramento em Educação, especialidade em Formação de Adultos no Instituto de Educação da Universidade de Lisboa. E-Mail: catarinadoutor@,campus.ul.pt
} 
main concerns of this article, which put an emphasis on the importance of young people and therefore their cultural practices in contemporary societies, are reflected on the following research questions: What does youth stand for? What is the meaning of being young in the world today? What are cultural practices understood? The article shows, therefore, how cultural practices are, fundamental to the daily lives of people, especially young people.

\section{KEYWORDS: YOUTH, LEISURE AND FREE TIME.}

\section{INTRODUÇÃO}

Ao longo do tempo, as pesquisas sobre o conceito de juventude têm, na verdade, ocupado um lugar de destaque na produção académica. A verdade é que a temática da juventude tem sido objeto de diversos estudos em várias áreas. Destas áreas científicas, destacam-se a sociologia, a psicologia, a antropologia, entre outras que analisam as mudanças físicas, psicológicas e comportamentais que ocorrem nos indivíduos neste período de vida. A este respeito, Silva (2002: 98 ) refere que

Nunca é demais sublinhar que os estudos sobre juventude vêm se configurando numa importante preocupação entre os pesquisadores e profissionais de várias áreas, uma vez que apontam para questões de âmbito sociocultural, educacional e econômico.

A noção de juventude, associada a um processo de transição entre estádios ou referente a uma faixa etária, encontra-se cada vez mais desatualizada. Tradicionalmente considerada como o período de vida que se estende da infância ou da adolescência à idade adulta, a noção de juventude sempre significou mais do que uma mera etapa do desenvolvimento físico-psicológico. Atualmente, esta noção encontra-se intimamente relacionada com o estatuto social que os jovens têm vindo a assumir nas sociedades ocidentais e industrializadas.

Ora, na segunda metade do século XIX, a visibilidade social da juventude tornou-se objeto de consciência social, reconhecendo os problemas e as tensões associados à temática. Este reconhecimento conduziu, então, à existência de uma «cultura adolescente». Neste sentido, entende-se por cultura adolescente como uma cultura mediática, de massas e frágil pois a entrada na vida adulta é cada vez mais tarde e difícil (Segalen, 1999). Na realidade, a necessidade do prolongamento da escolaridade, a própria configuração social da família contemporânea aliada à consequente dependência dos jovens face à família de origem, entre outras medidas de carácter público, constituíram a verdadeira expressão da visibilidade social dos problemas específicos da juventude.

Mas é efetivamente durante os anos 50 e 60, que o conceito de juventude emergiu como uma questão social, na medida em que os jovens se tornaram num problema, quer socialmente quer sociologicamente. Deste modo, a juventude é encarada como um «problema», sendo definida como protagonista de uma crise de valores e, de igual modo, de um conflito de gerações relativamente aos comportamentos éticos e culturais. Em Portugal, terá sido por volta de 1960 que a juventude começou a emergir como uma questão social e, consequentemente, como objeto de consciência social (Pais, 1994; Alves, 2008). Revoltados contra o regime político dessa altura e contra as gerações mais velhas, os jovens portugueses realçaram determinados problemas que os afetariam, nomeadamente a fraca capacidade de resposta por parte das universidades portuguesas e a própria imposição da 
guerra do Ultramar, entre outros. Desde então, o reconhecimento da existência de problemas sociais específicos que afetam particularmente a juventude em Portugal tem sido uma constante no "palco" científico nacional. Atualmente, a juventude sustenta problemas relacionados com o prolongamento desta fase de vida ecom o subsequente atraso na transição para o estado adulto. Aliás, o prolongamento da escolaridade e as dificuldades na obtenção do primeiro emprego são, precisamente, alguns dos exemplos desta situação.

A partir dos anos 70, a juventude quase se transformou uma categoria económica, visto que os jovens eram associados à crise económica e aos problemas por ela originados, particularmente problemas de emprego e da entrada na vida ativa. Neste sentido, a temática da juventude é, em si mesma, uma das mais significativas nas publicações científicas desde a década de 70. Os fenómenos relacionados com a juventude constituem-se como contributos importantes para determinar muitos dos aspetos das sociedades (Martins, 2000). Não obstante este crescente protagonismo, é a partir dos anos 80 que a problemática da juventude começa a ser objeto de um crescente interesse científico. Assiste-se, assim, a um aumento do protagonismo das investigações em torno da juventude nas ciências sociais que, por seu turno, tentam compreender os diversos fenómenos societais e as culturas juvenis (Campos, 2010).

\subsection{Juventude: um conceito construído socialmente}

Ao longo das últimas três décadas, o conceito de juventude tem sofrido algumas oscilações conceptuais, dado que era inicialmente entendida como uma fase de vida própria e, por conseguinte, detentora de uma aparente unidade. Num contexto de homogeneidade, predominava a procura de aspetos mais uniformes que caracterizavam esta fase de vida, ou seja, traços que faziam parte de uma cultura juvenil específica. Posteriormente, a postura sociológica que se impõe é de procurar não apenas as possíveis similaridades entre os jovens ou os grupos de jovens, mas sim, e fundamentalmente, as diferenças sociais que existem entre eles.

Deste modo, quando nos referimos a jovens estudantes, a jovens trabalhadores, a jovens em contexto urbano ou a jovens em contexto rural, percebemos que existem diferentes sentidos atribuídos à juventude. Reportamo-nos, assim, a diferentes juventudes, ou então, reconhecemos simplesmente a existência das diferentes culturas juvenis. Neste sentido, é crucial investigarmos a juventude a partir da sua heterogeneidade. Ora, em boa verdade, não existe uma só juventude, mas sim diferentes juventudes (Fernandes, 2001; Bourdieu, 2003; Santos, 2014). Desta forma, a juventude deve ser olhada na sua diversidade. Seguindo estas perspetivas teóricas, cremos que seria mais apropriado pensar na juventude como uma realidade socialmente construída, na qual se poderia obter várias leituras, a partir das condições culturais, sociais, económicas e políticas. Quer isto dizer que, a juventude é uma noção construída socialmente, que não pode ser definida tendo em consideração critérios exclusivamente biológicos, psicológicos, sociológicos, entre outros.

A generalização em torno da juventude pode, de igual modo, ser compreendida através do modo como as sociedades percebem esta etapa da vida, dando origem ao mito da juventude homogénea. Para Cecilia Braslavsky (1986, citado em Chaves, 2005) este consiste em identificar todos os jovens com alguns deles. Logo, as condições que legitimam a extensão da juventude para uns jovens são, assim, criadas no processo de identificação. Aliado a este processo, surge-nos a recusa desta condição por parte de outros jovens. O mito da juventude homogénea é fortalecido por fenómenos que aproximam os jovens no 
domínio do lazer. Esta teoria da juventude homogénea é desconstruída por José Machado Pais (2003) na sua obra intitulada "Culturas Juvenis". Na realidade, o autor defende que a juventude aparece socialmente dividida em função das suas origens sociais, perspetivas e interesses. Contudo, a juventude pode ser homogénea se a compararmos com outras gerações ou heterogénea se a encaramos como um conjunto de atributos sociais que diferenciam os jovens uns dos outros.

Por seu turno, Melucci (1997) considera a juventude como uma etapa da vida. Acrescenta ainda, que a juventude inicia-se quando a infância é abandonada e dá-se os primeiros passos para a vida adulta. Todavia, refere que é importante reconhecer as dificuldades e limitações de definição da categoria juventude como etapa da vida, pois não se trata de uma categoria homogénea. Muito pelo contrário, a juventude é uma categoria heterogénea, pois encontra-se submetida a um conjunto de fatores, nomeadamente cultura, classe, grupos, entre outros. Atualmente, a categoria de juventude encontra-se associada a ideias que vinculam a cronologia etária ou, por vezes, a imaturidade psicológica (Carrano, 2000). Uma das principais características da juventude é a irresponsabilidade. Muitos estudos sociológicos apontam como principais problemas da juventude a delinquência, o abuso de drogas e álcool, associando assim, o conceito de juventude à noção de irresponsabilidade e de problema social (Sposito, 2002; Alves, 2008). Aliás, a verdade é que juventude e problemas sociais passam a ser duas expressões indissociáveis e integrantes dos discursos científicos, políticos e do senso comum.

Neste sentido, torna-se importante compreender a juventude como uma variável complexa, na medida em que, se distingue pelas suas maneiras de existir em diferentes tempos e espaços sociais. É certo que a «cultura juvenil» requer, portanto, um espaço social próprio (Pais, 2003). Por conseguinte, a cultura juvenil é um mito, ou seja, uma construção social que existe mais como representação social do que como uma realidade. Para os jovens que fazem parte desse mito, o mesmo se transforma em realidade. Tal afirmação contribui para uma "consciência geracional" que conduz, claramente, os jovens a acentuar diferenças em relação a outras gerações. Por outro lado, os jovens que admitem não fazer parte deste mito, reconhecem que ser jovem é uma experiência diferente daquelas que os primeiros jovens viveram. Logo, a representação social da juventude dá lugar a uma realidade construída sociologicamente. Quer isto dizer que a desconstrução da juventude como representação social daria, assim, lugar a uma construção sociológica -científica e paradoxa- da juventude.

\subsection{A problemática da juventude na sociedade moderna}

Apesar das inúmeras dificuldades em definir o conceito de juventude, esta surge nas sociedades modernas como uma categoria fundamental. Ora, em boa verdade a juventude é cada vez mais um tema presente na sociedade contemporânea, quer nos espaços académicos quer nas políticas públicas (Silva, 2005). Muitas vezes, somos confrontados com a questão: “O que é ser jovem no Mundo Atual?". Torna-se, assim, importante estudar e compreender o papel desta temática na sociedade moderna. Abrantes (2003) enfatiza que as identidades juvenis se encontram em permanente transformação nas sociedades contemporâneas. A identidade juvenil consiste, na sua essência, num processo de contínua transformação, quer individual ou coletiva, num jogo de múltiplas experiências. É importante salientar que o universo juvenil, ou seja, os gostos, as práticas e as identidades 
constituem uma referência cultural em vários aspetos, como por exemplo, os consumos e os estilos de vida (Carrano, 2000; Fernandes, 2001).

Atualmente, existe um consenso relativamente à condição da juventude (Ribeiro, 2004) em que a juventude não é apenas uma condição biológica, mas que deriva de dinâmicas com múltiplas origens. Esta diversidade resulta, portanto, da teia de relações que se estabelecem em torno do jovem, que simultaneamente conferem significados e definem a sua inserção nas sociedades. No âmbito das relações dos jovens com as gerações adultas destacam-se as situações de conflito e de solidariedade que se expressam ao longo da vida. A condição juvenil apresenta-se como sendo uma construção recente, ou seja, uma categoria moderna. Correspondendo a uma etapa de excessivas definições de identidade pessoal e social, a condição juvenil requer um grau de elevada experimentação nas diversas esferas da vida. De certo modo, a condição juvenil reporta-se ao facto de os indivíduos viverem um período específico do ciclo de vida, num determinado momento histórico e cultural. Contudo, na sociedade contemporânea, assiste-se a um prolongamento da condição juvenil, principalmente devido aos longos percursos escolares (Pais, 2003).

Desta forma, o conceito de geração assume-se uma particular importância para a compreensão do papel da juventude nas sociedades modernas. Maia (2002) entende geração como um conjunto de indivíduos nascidos no mesmo tempo e que detêm uma experiência comum. Estes indivíduos expressam, simultaneamente, uma determinada maneira de encarar a vida, assim como os seus problemas. Ora ser jovem, na sociedade contemporânea, não é apenas uma condição biológica, mas sim uma maneira prioritária de definição cultural. A juventude contemporânea deixou de ser uma condição biológica e tornou-se, portanto, numa definição simbólica (Melucci, 1997). Quer isto dizer que as pessoas não são jovens apenas pela idade, assumem esta característica juvenil através da mudança cultural.

A temática da juventude contemporânea pode ser vista sob duas perspetivas: a primeira caracteriza a juventude como um problema social e a segunda descreve a juventude como uma solução para o futuro da humanidade. Na realidade, a juventude só se torna objeto de estudo enquanto representa uma ameaça para a sociedade ou até para si própria. Neste sentido, a delinquência e a rebeldia assumem uma importância fundamental na construção da problematização da juventude na sociedade moderna. Prevalece, assim, a ideia de que a juventude é uma etapa difícil e perturbada, principalmente devido às transformações ocorridas no processo de transição (Carvalho, 2002).

$\mathrm{O}$ conceito de juventude emerge, pois, como uma fase centrada na reivindicação do prazer e da independência, da qual resultam diversos conflitos com os pais, professores e polícias, originando, por vezes, atitudes de violência "descontrolada". Neste sentido, o jovem é um agente social direcionado para a realização futura, ou seja, a sua carreira profissional. Como mencionado, a juventude pode ser considerada como um problema para a sociedade como um todo, como também pode ser uma solução para a sociedade moderna, na medida em que, o segmento juvenil emerge, nitidamente, como uma potencialidade dentro de sua sociabilidade.

Alguns autores falam em "condição social da juventude", pois consideram que os jovens no seu grupo de pares partilham problemas e situações que os opõem aos outros grupos. Deste modo, a condição social da juventude passa a ser uma condição subordinada (Cruz et al., 1984). A juventude é, então, entendida como uma fase natural da vida, que envolve uma elevada naturalidade no estabelecimento de critérios para a sua delimitação. Partindo deste pressuposto, Olivier Galland (1991) entende juventude como uma fase de vida em que os seus membros se encontram na idade da espera, da dependência económica 
e da incerteza. Devido a algumas mudanças ocorridas no cenário mundial a partir dos anos 70, Galland (1991) constatou que a passagem para a vida adulta se tornou mais complexa. Este "prolongamento da juventude" pode, em grande medida, ser entendido como um aspeto positivo, da expansão da escolaridade ao contribuir para uma melhor inserção social e profissional. A partir desta perspetiva teórica, torna-se possível definir o prolongamento da juventude como o fenómeno que corresponde ao adiamento da transposição dos sucessivos patamares que dão acesso à idade adulta (Alves, 2008).

No entanto, Dubet (1996) propõe uma outra perspetiva em torno da juventude ao defender que para se estabelecer um tratamento analítico sobre esta problemática é necessário reconhecer que a condição moderna do jovem encerra uma tensão intrínseca. Aexperiência juvenil é construída, precisamente, em torno da formação moderna de um mundo juvenil autónomo.

\section{AS CORRENTES TEÓRICAS DA SOCIOLOGIA DA JUVENTUDE}

A verdade é que os jovens não vivem as situações de forma semelhante, pois cada um tem o seu próprio percurso individual, que varia consoante a especificidade do trajeto quotidiano. $\mathrm{Na}$ realidade, não existe um único conceito de juventude que abranja os diferentes campos semânticos. Devemos, por isso, falar em juventudes e não em juventude, devido à heterogeneidade do conceito. Existem, portanto, diferentes maneiras de ser jovem de acordo com a intensa heterogeneidade que se observa no plano económico, social e cultural. A juventude deve ser, então, compreendida como um fenómeno sociocultural inserido numa sociedade dinâmica e complexa. Neste sentido, Margulis (2001: 45) afirma que «a juventude deve ser analisada como uma condição relacional determinada pela interação social, cuja matéria básica é a idade processada pela cultura». Para compreendermos as condições sociais que envolvem o ser jovem nos tempos contemporâneos, é necessário termos em consideração as três correntes da juventude: a corrente geracional, a corrente classista e a corrente das culturas juvenis (Pais, 2003).

\subsection{Corrente Geracional}

A corrente geracional sustenta o conceito de juventude como uma fase da vida e salienta a importância do aspeto unitário da juventude. De acordo com Pais (2003), em qualquer sociedade existem várias culturas dominadas e/ou dominantes que se desenvolvem no quadro de um sistema dominante de valores. Para o autor, o sistema dominante de valores assenta em dois tipos de teorias: por um lado, a teoria da socialização e a teoria das gerações, por outro lado. Nas teorias funcionalistas da socialização, os conflitos ou descontinuidades intergeracionais são vistos como «disfunções nos processos de socialização que respeitam à juventude tomada no sentido de fase de vida» (Pais, 2003:38). Por conseguinte, a teoria das gerações procura explicar as crises geracionais enquanto descontinuidades intergeracionais. Para os defensores da teoria das gerações, as descontinuidades intergeracionais constituem uma condição sine qua non para a existência desta teoria. Se existisse um movimento continuo, não haveria uma geração após outra e, naturalmente, não haveria uma teoria das gerações (Idem). Portanto, as descontinuidades intergeracionais estão na base da formação da juventude como uma geração social.

Curiosamente, em Portugal, alguns anos antes, já Nunes (1968) defendia que cada geração social só pode ser determinada consoante a auto-referência a outras gerações. 
Sendo assim, a corrente geracional assenta na existência de uma cultura juvenil que se opõe à cultura de outras gerações, nomeadamente as gerações adultas. Todavia, esta oposição pode assumir diferentes tipos de descontinuidades intergeracionais, nomeadamente as crises ou conflitos intergeracionais.

Nos anos 50, as teorias da socialização predominavam, quando os psicólogos e os médicos detinham em seu poder o monopólio do discurso sobre os jovens. Na realidade, os psicólogos e os médicos compreenderam a juventude como um período de difícil amadurecimento psicológico que deveria conduzir à idade adulta. É, certamente, durante este período que o conceito de identidade adquire uma extrema importância. Atualmente, o conceito de identidade é bastante utilizado nas diversas Ciências Sociais. Neste sentido, Dubar (1997:13) refere que a identidade de alguém é «aquilo que ele tem de mais precioso: a perda de identidade é sinónimo de alienação, de sofrimento, de angústia e de morte». Ora, a identidade humana não nos é dada ao nascer, mas constrói-se na infância e deve reconstruir-se, posteriormente, ao longo da vida. Desta maneira, a identidade é, sem sombra de dúvidas, um produto de consecutivas socializações.

Segundo os autores desta corrente geracional, as experiências de determinados indivíduos são compartilhadas por outros indivíduos da mesma geração, que vivem situações semelhantes e que, por vezes, enfrentam problemas idênticos. Contudo, não significa que diferentes perspetivas de vida não possam ser partilhadas por diferentes membros de uma mesma geração. Importa, assim, realçar que a valorização da problemática da juventude justifica-se em função dos sinais de continuidade e descontinuidade intergeracionais. Estes sinais manifestam-se de duas formas: de um lado, são alvos de processos de socialização, através de instituições sociais específicas, particularmente a escola ou a família. Assim, as gerações mais novas interiorizam e reproduzem no seu quotidiano um conjunto de crenças, valores, normas e símbolos característicos das gerações adultas, em termos de continuidade. Por outro lado, visto essa interiorização de sinais não ser realizada de um modo passivo, originam-se frações culturais entre as várias gerações, instituições sociais dominadas pelas gerações mais velhas, em termos de descontinuidade.

De acordo com os defensores da socialização contínua, a participação das novas gerações na vida social apresenta as duas características muito importantes, nomeadamente a socialização dos jovens e a juvenilização da sociedade. Por um lado, a socialização dos jovens processa-se através dos mecanismos que possibilitam a integração dos jovens no sistema de relações sociais. Quando se fala em "socialização da juventude", é atribuído um papel passivo de assimilação de normas e valores aos jovens. Por outro lado, na juvenilização da sociedade verifica-se que os jovens influenciavam os adultos ${ }^{2}$. As contribuições trazidas por Morin (1962) e, posteriormente, por Galland (1991) sobre este tema remetem-nos para o facto de que a cultura juvenil se insere na sociedade através do consumo e dos seus modelos. Portanto, a juvenilização implica que a «sociedade modele a juventude à sua imagem mas, ao mesmo tempo, se rejuvenesça» (Pais, 2003: 42). Porém, foram elaboradas algumas críticas à corrente geracional, particularmente o olhar a juventude como uma entidade homogénea. Normalmente, a juventude é vista como uma categoria etária, na medida em que, a idade é considerada uma variável mais importante que as variáveis socioeconómicas. A questão das relações intergeracionais, para a corrente

\footnotetext{
${ }^{2}$ A tese da juvenilização da sociedade é proposta em 1962 por Edgar Morin, sendo mais tarde retomada por Olivier Galland em 1991.
} 
geracional, é uma questão fundamental porque expressa a problemática central da reprodução social. Com efeito, a reprodução social restringe-se à análise da conservação dos conteúdos existentes nas relações sociais de gerações.

Em boa verdade, a corrente geracional define as culturas juvenis por oposição à cultura dominante das gerações mais velhas. Por conseguinte, as subculturas juvenis são entendidas funcionalmente como culturas "desviantes" relativamente à cultura dominante das gerações mais velhas.

\subsection{Corrente Classista}

Na corrente classista, a reprodução social é, na sua essência, vista no âmbito da reprodução das classes sociais. Neste sentido, entende-se por reprodução social como o processo mediante o qual uma sociedade, através de diferentes mecanismos, reproduz a sua própria estrutura (Maia, 2002). A verdade é que alguns trabalhos desenvolvidos nesta corrente apresentam-se como críticos ao conceito de juventude. Consideram a juventude enquanto uma categoria social, que mais cedo ou mais tarde, acabará por ser dominada por uma relação de classe (Fernandes, 2001; Pais, 2003; Pappámikail, 2010). Todavia, a juventude enquanto categoria dissolvia-se, segundo Chamboredon (1985), numa diversidade essencial recoberta pelas diversas classes sociais. Nesta linha de pensamento, a classe social consiste num conjunto de indivíduos que se relacionam e agem de uma maneira similar quando são confrontados com constrangimentos (Maia, 2002). Normalmente a classe social está associada a uma cultura, isto é, a um conjunto de normas e práticas que condicionam a existência dos indivíduos e exprimem-se em determinados comportamentos. Já Bourdieu afirma que as classes sociais não existem e "O que existe é um espaço social, um espaço de diferenças, no qual as classes existem de algum modo em estado virtual, pontilhadas, não como um dado, mas como algo que se trata de fazer" (2001:26-27).

Nesta lógica de pensamento, as classes sociais são apenas classes lógicas, determinadas pela delimitação de um conjunto relativamente homogéneo de agentes que ocupam uma posição idêntica no espaço social.

Esta corrente defende ainda que, normalmente, a transição dos jovens para a vida adulta é acompanhada por desigualdades sociais na divisão sexual do trabalho, na condição social, entre outras. Contudo, os jovens de diferentes condições sociais partilham, de igual modo, o receio do desemprego, ainda que recorram a diversas estratégias para contornar os possíveis problemas que possam surgir. Para esta corrente, as culturas juvenis são, elas mesmas, formas de resistência à cultura da classe dominante. Neste sentido, quando uma cultura juvenil ganha ascendência sobre outra cultura, esta torna-se a base de uma ideologia dominante. Entendidas como produto de relações antagónicas de classe, as culturas juvenis são sempre culturas de classe. Sendo assim, estas culturas apresentam-se como culturas negociadas num contexto cultural determinado por relações de classe, ou seja, culturas de resistência. Nesta corrente, a delinquência juvenil emerge como uma forma de resistência deliberada e consciente aos valores da classe dominante.

É ainda importante realçar que a corrente classista entende as culturas juvenis como subculturas ou subprodutos da cultura hegemónica de uma classe dominante que possivelmente se irá impor. Nesta perspetiva, uma subcultura pode ser entendida como um estilo de vida desenvolvido por grupos que ocupam posições estruturais subordinadas, numa determinada sociedade. Surge, assim, como uma forma de resposta aos modos de expressão dominantes, demonstrando uma tentativa de resolver as contradições estruturais 
que aparecem num contexto societal mais vasto (Maia, 2002). Com efeito, as culturas juvenis «seriam as "soluções de classe" a problemas compartilhados por jovens de determinada classe social» (Pais, 2003:48). Posto isto, as culturas juvenis que não se manifestam como culturas de resistência "classista" não constituem objeto de estudo da corrente classista. As culturas de classe têm sempre um significado político, na medida em que os rituais destas culturas manifestam uma capacidade de resistência, alcançando e criando espaços culturais. Como esta capacidade de resistência é mais visível nos rapazes, esta corrente classista orienta-se mais para o estudo das culturas juvenis masculinas. Contudo e curiosamente, foram as feministas que começaram por estudar as culturas femininas com o propósito de evidenciar a sua subordinação à divisão sexual do trabalho e ainda a necessidade do matrimónio como forma de relativa emancipação. Todavia, estas acabaram por cair no mesmo erro daqueles que tanto criticaram, ao considerar os universos femininos e masculinos como dois universos mutuamente exclusivos.

\subsection{Cultura Juvenil}

José Machado Pais (2003) tenta estabelecer uma comparação entre a corrente denominada cultura juvenil e as duas correntes apresentadas anteriormente: a corrente geracional e a corrente classista. Contrariamente às duas correntes anteriores, a corrente designada cultura juvenil pode ser entendida como

O sistema de valores socialmente atribuídos à juventude, isto é, valores a que aderirão jovens de diferentes meios e condições sociais (...). É admissível que alguns aspetos das culturas juvenis podem prevalecer ou não segundo os meios sociais e trajetórias de classe em que os jovens se inscrevem (Pais, 2003:54).

Nas últimas décadas, a cultura juvenil tem vindo a apresentar uma maior visibilidade, a partir das transformações ocorridas na sociedade (Waiselfisz, 2004). No entanto, essa cultura não é homogénea, variando de acordo com a situação de classe, e mesmo dentro desta não se pode estabelecer a priori que todos os jovens tenham o mesmo tipo de comportamento.

No âmbito da sociologia da juventude, a noção de cultura tem sido predominantemente utilizada com o desígnio de distinguir os diferentes significados e valores de determinados comportamentos juvenis. É certo que as culturas juvenis são encaradas como processos de internalização de normas nos processos de socialização e, por isso, estas culturas juvenis têm sido analisadas ao nível das representações sociais dominantes. Neste sentido, a noção de juventude explora o sentido antropológico em que as práticas do dia-a-dia e os modos de vida específicos revelam determinados significados e valores ao nível da própria vida quotidiana e das instituições.

A socialização adquire, pois, distintos significados de acordo com as perspetivas de análise que desenvolveram este conceito. Em primeiro lugar, a socialização analisa, na sociedade, a transmissão de normas de gerações ou de classes sociais (macrossociológico). E em segundo lugar, a socialização tem sido utilizada a um nível microssociológico, onde os indivíduos nos seus quotidianos reproduzem ou modificam as normas. Deste modo, os jovens partilham linguagens e valores diferentes porque se "movimentam" em diferentes contextos sociais. A este respeito, Demartis (2002:43) define socialização como

O processo mediante o qual os indivíduos e os grupos aprendem e interiorizam as normas culturais e os valores próprios do contexto social de pertença. Trata-se de um 
processo elaborativo que, desde a primeira infância, se estende à idade adulta, segundo fases e modalidades diferentes.

A socialização é, portanto, o processo que permite a transmissão de normas sociais de uma geração a outra. Devido ao facto de se encontrarem em diferentes contextos sociais, os jovens partilham diferentes valores. Ora, em boa verdade, não é possível compreender as culturas juvenis sem entender o significado que os jovens atribuem às suas ações ou às suas atividades quotidianas (Pais, 2003). A verdade é que no dia-a-dia que os jovens constroem as suas formas sociais de compreensão e de entendimento que se articulam com as formas específicas de consciência, de pensamento e de perceção. É precisamente no quotidiano que os jovens tecem os seus projetos existenciais e transformam, ao mesmo tempo, o seu lugar na realidade social (Hack, 2005). Neste sentido, os tempos quotidianos dos jovens se encontram intimamente associados às práticas culturais e de lazer.

\section{PRÁTICAS CULTURAIS DOS JOVENS}

Atualmente, somos também confrontados com o conceito de Cultura. No entanto, algumas questões pairam no ar, como por exemplo: O que é a Cultura, ou seja, o que significa o conceito de cultura? De que falamos quando falamos em cultura? Para Giddens (2002:36), a cultura refere-se aos modos de vida dos membros de uma sociedade, ou de grupos pertencentes a essa sociedade; «inclui o modo como se vestem, as suas formas de casamento e família, os seus padrões de trabalho, cerimónias religiosas e atividades de lazer». Neste sentido, a cultura pode ser entendida como «um lugar específico de produção de sentido que viabiliza o estabelecimento de relações significantes entre os homens e o mundo em que vivem» (Pais, 1994: 53). Deste modo, podemos verificar que são diversos os significados que vários autores conferem ao conceito de cultura. Com efeito, a noção de cultura conduz-nos diretamente às práticas culturais. Em boa verdade, no âmbito das práticas culturais,

Existe aí um imenso campo de pesquisa, mais ainda porque não nos podemos contentar em estudar estas práticas culturais em si mesmas. São, também, com efeito, as suas eventuais correlações com os lugares e os meios que convém analisar, já que a história cultural é inseparável de sua estrutura básica social e permanece bem uma história de afastamentos, marcantemente sociológicos e geográficos, em certos aspetos (Sirinelli, 2004: 15-16).

Sendo assim, as práticas culturais de uma determinada população não podem ser estudadas isoladamente, têm que ser contextualizadas num determinado momento histórico. $\mathrm{Na}$ verdade, o estudo das práticas culturais é uma atividade relativamente recente na tradição científica portuguesa. Somente a partir dos finais dos anos 80 se iniciaram os estudos sistemáticos sobre as práticas culturais dos portugueses. Nos anos 90, surgiram algumas pesquisas intensivas preocupadas com o uso da cultura no dia-a-dia e baseadas em estudos de casos. Torna-se, deste modo, importante definirmos o conceito de práticas culturais, como «a ocupação dos tempos livres, ou do tempo de lazer, de uma dada população» (Mendonça, 2001: 97). O conceito de práticas culturais é, claramente, caracterizado como um conceito multidimensionalizado e amplo.

No que concerne à análise das práticas culturais, propriamente ditas, esta se realiza em duas dimensões de análise: de um lado, a esfera da vida quotidiana e domiciliária, e de outro lado, as saídas e consumos culturais menos frequentes. De acordo com Mendonça (2001), o campo dos lazeres encontra-se organizado em duas esferas: a esfera «endo- 
domiciliar» e a esfera «exo-domiciliar». Enquanto na primeira esfera, o telespectador, ouvinte e leitor pode usufruir de uma maneira partilhada de bens ou emissões culturais, a segunda esfera é composta por um conjunto de saídas que mobilizam investimentos, interesses e trocas com o exterior. Na realidade, a esfera endo-domiciliar exerce um enorme domínio na ocupação dos tempos livres das pessoas. A par disso, o consumo domiciliário é constituído por ofertas de indústrias culturais, nomeadamente a indústria da informação (imprensa) e a indústria de múltiplo (livros).

A este respeito, Lopes (2000) define uma tipologia das práticas culturais: práticas culturais e as práticas de lazer e entretenimento. No primeiro caso, a ida a um concerto de música clássica, espetáculo de dança, ao teatro, ao cinema, ao museu, a uma biblioteca/livraria, entre outros, são consideradas práticas de carácter clássico, próprias de uma cultura legitimada (Fernandes, 2001). Quanto às práticas de lazer e de entretenimento, são consideradas como indicadores de uma "cultura de saídas", na medida em que, incluem sair com os amigos(as), sair para dançar, frequentar cafés, shoppings, entre outros. Não podemos deixar de referir as atividades que são praticadas em casa, nomeadamente, ver televisão, ouvir rádio, ler revistas ou jornais.

É neste contexto que a "cultura de saídas" ganha especial relevância e revela-se crucial para constatarmos a importância das práticas culturais nos tempos livres. Os reflexos de juvenilidade traduzem a importância da cultura de saída dos jovens. Na realidade, os jovens são os protagonistas de uma "cultura de saídas" e, simultaneamente, os maiores frequentadores dos equipamentos culturais urbanos. A cultura de saídas é, assim, uma cultura essencialmente direcionada para o cinema, os cafés, os centros comerciais e as discotecas. Por outro lado, as idas a exposições e a museus, o teatro e os concertos apresentam valores muito reduzidos. Seguindo esta linha de pensamento, Mendonça (2001) afirma que as práticas habitualmente classificadas como indicadores de uma cultura de saídas apresentam, regra geral, valores reduzidos. É neste sentido, que podemos estabelecer uma ligação entre a cultura de saídas e o espaço público, na medida em que a "cultura de saídas" deve conferir diversidade e dinamismo ao espaço público.

O espaço público remete-nos para a teoria crítica da Escola de Frankfurt, mais concretamente Habermas. A esfera pública é, para Habermas (1991) um espaço onde tudo se torna visível a todos longe dos espaços privados. Partilhando da mesma opinião que Habermas, Scheid (2006: 4) acrescenta que o «espaço público não se constrói unicamente no domínio das instituições, mas também no quotidiano, no que está relacionado à vida e às particularidades dos indivíduos». Deste modo, a esfera pública é construída por diversos públicos que se organizam em torno de temas de interesse comum. Fortuna e Silva (2001: 444-445) salientam a importância da esfera doméstica

Como [um] patamar de acesso aos espaços públicos, [em que a] casa pode ser vista como um espaço de abertura ativa (e não apenas de passiva recetividade) a tudo o que se passa no mundo e não mais apenas um lugar recatado de privacidade ou repouso, posto à margem das tendências convulsivas de política ou de cultura.

A noção de espaço público é colocada em perigo, uma vez que os espaços são apropriados consoante o capital lúdico dos grupos. Em boa verdade, o capital lúdico assume-se, portanto, como uma «detenção de capitais de valor central na hierarquia de bens socialmente produzidos» (Baptista, 2004: 5). Este capital lúdico engloba o capital económico, o social e o cultural. Relembrando a perspetiva de Bourdieu (2003), é importante frisar a definição do habitus enquanto o processo de inculcação de determinados padrões culturais nos indivíduos, produzido pela socialização. Neste sentido, o capital 
económico representa o conjunto dos bens e recursos económicos, como é o caso do rendimento profissional. Já o capital social é constituído pelo conjunto de relações sociais que o indivíduo dispõe e que está em condições de mobilizar quando sente necessidade de o fazer. E, por último, o capital cultural constitui o conjunto de recursos intelectuais e culturais que são adquiridos através da educação familiar e escolar, nomeadamente os diplomas. Neste sentido, o acesso aos bens culturais depende da existência de um capital escolar elevado. A intensidade das práticas culturais encontra-se relacionada com a posse de um alto grau de escolaridade, que se verifica em quase todas as atividades culturais: cinema, leitura, música, teatro. Em síntese, os estudos de Bourdieu (2001) revelam que a quantidade acumulada de capital (económico, cultural, social) determina as classes sociais. De acordo com a teoria classista, as classes sociais são distinguidas em função da sua posse de capitais, assim como das suas práticas e gostos culturais. Sendo assim, o padrão de consumo de cada indivíduo, identificado pelo habitus, revela a posição do indivíduo na hierarquia social.

Os territórios que têm sido concebidos como espaços lúdicos estão intimamente ligados ao modo de vida lúdico. Este modo de vida ocupa um lugar de destaque nas sociedades, na medida em que, o acesso a bens económicos e sociais é generalizado e se constata um alargamento das expectativas de bem-estar e de conforto a uma grande parte da população. Os espaços lúdicos urbanos devem ser, essencialmente, espaços de lazer, ou então lugares de dinâmica cultural que proporcione às pessoas momentos de lazer.

Partindo do pressuposto que as práticas culturais constituem uma entrada fundamental para observar o lazer, podemos referir que o conceito de lazer democratizou o conceito de prática cultural. Seguindo Gomes (2005: 56), o lazer não é uma realidade homogénea, dado que as suas práticas «provém de múltiplos determinismos, económicos uns, individuais outros, sociais todos». Atualmente o conceito de lazer constitui um objeto de estudo da Sociologia. Contudo, nos últimos anos, o conceito e o significado de lazer têm-se vindo a alterar. Mota (1997) realça que alguns autores consideram o lazer como o produto da industrialização e do desenvolvimento da sociedade moderna, identificando-se e associando-se ao processo de urbanização e de desenvolvimento das cidades.

Dumazedier (2001), por seu turno, refere que a importância do lazer foi notória desde o nascimento da sociedade industrial, na medida em que com a redução do trabalho industrial, surge mais tempo livre. Contudo, verifica-se também uma fraca promoção geral do lazer. Entende-se, assim, por lazer como

Um conjunto de ocupações às quais o indivíduo pode entregar-se de livre vontade, seja para repousar, seja para divertir-se, recrear-se e entreter-se ou ainda para desenvolver sua formação desinteressada, sua participação social voluntária, ou sua livre capacidade criadora, após livrar-se ou desembaraçar-se das obrigações profissionais, familiares e sociais (Idem: 34).

$\mathrm{Na}$ realidade, os jovens diferenciam-se nos lazeres que dispõem e também manifestam diferentes comportamentos de classe no lazer. Por conseguinte, as diferentes vivências de lazer na juventude encontram-se ligadas àstrajetórias da família, realizam-se e incorporamse na escola, originando posições diferentes nas várias dimensões da vida social. Sendo assim, o lazer reflete os valores culturais da família e do status que representa. Importa ainda realçar que a ideia de tempo livre encontra-se intimamente associada à noção de lazer (Pinheiro, 2000). Apesar de muitas vezes serem confundidos, Mota (1997) considera que os conceitos de lazer e de tempo livre não têm o mesmo significado. Ora, para existir lazer tem que existir tempo livre, não significa necessariamente que todo o tempo livre seja lazer. 
Desta forma, o tempo livre é uma condição necessária mas não suficiente para o lazer (Ventosa, 2003).

Uma grande parte da sociologia da juventude tem-se dedicado à sociologia do lazer. Pais (2003) menciona que o interesse da sociologia da juventude pelo lazer tem originado algumas perspetivas teóricas polémicas. Em primeiro lugar, surge-nos a perspetiva de olhar o lazer juvenil como um domínio de práticas culturais homogéneas devido à particularidade de serem específicas e exclusivas de uma fase de vida que aparece ligada à juventude. De uma forma geral, o aspeto controverso desta perspetiva reside no facto de a juventude ser entendida como uma realidade homogénea. A outra perspetiva considera as práticas culturais juvenis como «normativamente marginais relativamente à cultura dominante que seria específica das gerações mais velhas» (Idem:133). Esta perspetiva também se apresenta questionável. Dado que as culturas juvenis se encontram afastadas do sistema normativo característico das gerações adultas, não significa que os jovens não consigam produzir as suas próprias normas.

Atualmente, o lazer é um fenómeno que se tem vindo a expandir e que abrange, simultaneamente, uma multiplicidade de práticas culturais. Nas sociedades modernas, os tempos livres constituem uma dimensão importante na vida das crianças, dos jovens e adultos. São, por isso, entendidos como um "direito de todos", valorizando-se o lazer.

\section{CONSIDERAÇÕES FINAIS}

Dada a complexidade da temática, que significado(s) poder-se-á então atribuir ao conceito de juventude? Em que consiste exatamente a juventude? Nada mais do que um vasto conjunto de opiniões divergentes a partir dos quais não se consegue chegar a um consenso. A verdade é que a juventude surge cada vez mais associada a um conjunto diversificado de modos de vida e cada vez menos a uma categoria de idade (Pais, 2003). Neste sentido, a juventude constitui uma categoria socialmente construída e sujeita a diversas modificações ao longo do tempo. Enquanto objeto sociologicamente inquietante e desafiador, a juventude tende a estender-se e, simultaneamente, prolongar-se no tempo (Galland, 1991; Pappámikail, 2010). É neste sentido que as práticas culturais e especificamente o lazer assumem uma posição privilegiada na vida dos jovens, na medida em que proporcionam diversão, desenvolvimento pessoal, entre outros. Enfim, que podemos então concluir senão que as práticas culturais dos jovens se apresentam como um tema polémico e suscetível de assumir diversos significados? No fundo, esta problemática constitui-se como um conceito que permanece algo ambíguo, na medida em que recebe diferentes sentidos nos diversos contextos culturais. Cremos, pois, que daqui podem resultar algumas reflexões para uma melhor compreensão da juventude, ou se preferirmos das juventudes, e principalmente uma melhor compreensão das práticas culturais e da sua influência nos jovens. Pelo exposto, é fundamental olharmos para estas temáticas - juventude e práticas culturais - e, ao mesmo tempo, refletirmos acerca do papel delas na sociedade atual, procurando perceber a realidade tal como ela existe e tal como é produzida e alterada.

LISBOA (PORTUGAL), MARZO 2016

RECIBIDO: MARZO 2016

ACEPTADO: JULIO 2016 


\section{REFERÊNCIAS BIBLIOGRÁFICAS}

ABRANTES, PEDRO (2003). «Identidades Juvenis e Dinâmicas de Escolaridade». Sociologia, Problemas e Práticas №41. Lisboa.

ALVES, NATÁLIA (2008). Juventudes e Inserção Profissional. Lisboa: Educa/UI\&DCE.

BAPTISTA, LUÍS VICENTE (2004). «Territórios Lúdicos (E o que torna Lúdico um Território): ensaiando um ponto de partida». Coimbra: Atas do V Congresso Português de Sociologia.

BOURDIEU, PIERRE (2001). Razões Práticas sobre a Teoria da Acção. Oeiras: Celta Editora.

---- --- (2003). Questões de Sociologia. Lisboa: Fim de Século Edições.

CARRANO, PAULO (2000). «Juventudes: as Identidades são múltiplas». Movimento: Revista da Faculdade de Educação da Universidade Federal Fluminense, $N^{\circ} 1$. NiteróiRio de Janeiro.

CARVALHO, GIANE ALVES DE (2002). O jovem nas Políticas Municipais de Florianópolis. Florianópolis: Universidade Federal de Santa Catarina.

CHAMBOREDON, JEAN-CLAUDE (1985). «Adolescence et post-adolescence: la 'juvénisation'». In: Anne-Marie Aleon, Odile Morvan, et Serge Lebovici: Adolescence terminée, Adolescence interminable. Paris: PUF.

CHAVES, MARIANA (2005). «Juventud Negada Y Negativizada: Representaciones y formaciones discursivas vigentes en la Argentina contemporánea». Última Década No23.Valparaíso: Ediciones CIDPA.

CAMPOS, RICARDO (2010). «Juventude e visualidade no mundo contemporâneo: uma reflexão em torno da imagem nas culturas juvenis». Sociologia, Problemas e Práticas $\mathrm{N}^{\circ} 63$.

CRUZ, MANUEL BRAGA et al. (1984). «A condição social da juventude portuguesa». Análise Social V. XX No 81-82.

DEMARTIS, LÚCIA (2002). Compêndio de Sociologia. Lisboa: Edições 70.

DUBAR, CLAUDE (1997). A Socialização: Construção das Identidades Sociais e Profissionais. Porto: Porto Editora.

DUBET, FRANÇOIS (1996). «Des jeunesses et des sociologies: les cas français». Sociologie et Sociétés Vol. $28 \mathrm{~N}^{\circ} 1$.

DUMAZEDIER, JOFFRE (2001). Lazer e cultura popular. São Paulo: Perspectiva.

FERNANDES, ANTÓNIO TEIXEIRA (Coord.) (2001). Estudantes do Ensino Superior no Porto: Representações e Práticas Culturais. Porto: Edições Afrontamento.

FORTUNA, CARLOS E SILVA, AUGUSTO SANTOS (2001). «A cidade do lado da cultura: espacialidades sociais e modalidades de intermediação cultural». In: BoAventura De Sousa SANTos (org.): Globalização: fatalidade ou utopia? Porto: Edições Afrontamento.

GALLAND, OLIVIER (1991). Sociologie de la jeunesse. Paris: Armand Colin.

GIDDENS, ANTHONY (2002). Sociologia. Lisboa: Fundação Calouste Gulbenkian.

GOMES, RUI MACHADO (2005). Os Lugares do Lazer. Lisboa: Instituto do Desporto de Portugal.

HABERMAS, JÜRGEN (1991). The Structural Transformation of the Public Sphere. An Inquiry into a Category of Bourgeois Society. Cambridge: MIT Press. 
HACK, CÁSSIA (2005). «Lazer e Mídia em Culturas Juvenis: uma abordagem da vida cotidiana».Dissertação (Mestrado em Educação Física). Florianópolis: Universidade Federal de Santa Catarina.

LOPES, JOÃO TEIXEIRA (2000). A cidade e a cultura. Um estudo sobre práticas culturais urbanas. Porto: Edições Afrontamento.

MAIA, RUI LEANDRO (Coord.) (2002). Dicionário de Sociologia. Porto: Porto Editora.

MARGULIS, MARIO (2001). «Juventude uma aproximación conceptual». In: SoLUM Donas BuraK (org.). Adolescencia y Juventud en América Latina. Cartago: Libro Universitario Regional.

MARTINS, ERNESTO C. (2000). «Jovens versus juventude no final do milénio: política de Juventude». Ensino Magazine (Jornal Reconquista), Ano III, No32.

MELUCCI, ALBERTO (1997). «Juventude, tempo e movimentos sociais». Revista Brasileira de Educação No5/6. São Paulo: ANPED.

MENDONÇA, CARLOS JOSÉ (2001). Políticas, Práticas Culturais e Públicos de Teatro no Algarve. Lisboa: Edições Colibri.

MOTA, JORGE (1997). A actividade física no lazer: reflexões sobre a sua prática. Lisboa: Livros Horizonte.

NUNES, ADÉRITO SEDAS (1968). Sociologia e ideologia do desenvolvimento. Lisboa: Moraes Editores.

PAIS, JOSÉ MACHADO (Coord.) (1994). Práticas Culturais dos Lisboetas: Resultados do inquérito em 1994 aos habitantes da Grande Lisboa. Lisboa: Instituto de Ciências Sociais da Universidade de Lisboa.

---- ---- (2003). Culturas Juvenis. Lisboa: Imprensa Nacional Casa da Moeda.

PAPPÁMIKAIL, LIA (2010). «Juventude(s), autonomia e sociologia: questionando conceitos a partir do debate acerca das transições para a vida adulta». Sociologia: Revista do Departamento de Sociologia da FLUP V. XX.

PINHEIRO, CARLA MARIA (2000). Consumo de Massas e Estilos de Vida: Comportamentos, Simbolismo e Vice-Versa. Coimbra: Atas do IV Congresso Português de Sociologia.

RIBEIRO, JORGE CLÁUDIO (2004). «Os Universitários e a Transcendência - Visão Geral, Visão Local». REVER, Revista de Estudos da Religião, No2.

SANTOS, CRISTINA ALEXANDRA (2014). Os jovens, o consumo e a identidade: uma trilogia contemporânea? $O$ consumo de marcas de vestuário e de calçado $e$ a construção identitária juvenil. Tese de doutoramento (Sociologia). Lisboa: ISCTE Instituto Universitário de Lisboa.

SCHEID, DAIANE (2006). «Espaço Público e Visibilidade Institucional na Sociedade da Informação». Revista Razón Y Palavra Nº52.

SEGALEN, MARTINE (1999). Sociologia da Família. Lisboa: Terramar.

SILVA, ANTÓNIO CARLOS (2001). «A subjectividade da categoria Juventude». Psicopedagogia Online.

SILVA, CRISTIANE FERNANDES (2005). «Resenha de Retratos da juventude brasileira: análises de uma pesquisa nacional». Tempo Social. Revista de Sociologia da USP V. 17 $\mathrm{N}^{\mathrm{o}} 2$.

SILVA, VANDA (2002). «Jovens de um Rural Brasileiro: Socialização, Educação e Assistência». Cadernos Cedes V. 22 No57. Campinas.

SIRINELLI, JEAN-FRANÇOIS (2004). «Este século tinha sessenta anos: a França dos sixties revisitada». Revista Tempo V. 8 N$^{\circ} 16$. Rio de Janeiro. 
Última DÉCADA Nº45, ProyeCto JUVENTUDES, DiCIEMBRE 2016, PP. 159-174

SPOSITO, MARÍLIA PONTES (2002). Juventude e escolarização (1980/1998). Brasília: MEC/INEP/Comped (Estado do Conhecimento, 7).

VENTOSA, VÍCTOR (2003). «Ocio y Tiempo Libre». In: Víctor Ventosa (coord.) Manual del Monitor de Tiempo Libre. Madrid: Editorial CCS.

WAISELFISZ, JÚLIO JACOBO (2004). Relatório de Desenvolvimento Juvenil - 2003. Brasília: UNESCO - Edição publicada pelo Escritório da UNESCO no Brasil. 